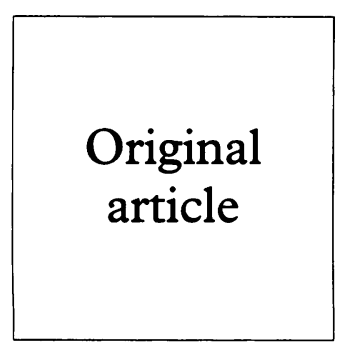

\section{Serological markers for treponemal infection in children in rural Kilimanjaro, Tanzania: evidence of syphilis or non-venereal treponematoses?}

\author{
Elise Klouman, Elisante J Masenga, Noel E Sam
}

Objective: To determine the seroprevalence of treponemal infection and possible risk factors
among children aged 0-14 in the general population of a rural Tanzanian village.
Methods: The survey was conducted as a part of a cross sectional study of a total village popu-
lation on HIV and sexually transmitted diseases. Among 1708 registered children aged 0-14, the
553 first attending were tested for treponemal infection with both rapid plasma reagin test (RPR के
and Treponema pallidum haemagglutination test (TPHA). These children belonged to a house-
hold cohort-also including their parents, siblings, and other household members-with 1339
members; 1224 ( $91 \cdot 4 \%$ participated in the survey and $82 \cdot 1 \%$ of these were tested for treponemal
infection.

Results: The overall prevalence for the TPHA test was $6 \cdot 4 \%$ among girls and $1 \cdot 1 \%$ among boys (odds ratio, $\mathrm{OR}=6 \cdot 5 ; 95 \%$ confidence interval, $\mathrm{CI}: 1 \cdot 9-22 \cdot 3$ ). The sex difference was most pronounced in the age group $10-14 ; 11.1 \%$ among girls versus $1.0 \%$ among boys $(\mathrm{OR}=12 \cdot 8$; CI: 1.6-101.9). Among the 20 children who were TPHA positive, we found two cases of active, congenital syphilis. There was a lack of association between positive serology in children and positive serology in their parents.

Conclusion: The highly significant predominance of girls testing positive for TPHA, and the concomitant lack of association between parents' and children's serostatus might point to sexual transmission as being the most common route of transmission of treponemal infection in girls during childhood in this village. The sources of infection for the seropositive girls are possibly found outside the family.

(Genitourin Med 1997;73:522-527)

Keywords: treponemal infection; syphilis; children; sexual abuse; Africa

\section{Introduction}

Treponemal infection in children can be either syphilis; congenital, or venereal, which is most often transmitted through sexual abuse, ${ }^{12}$ or a non-venereal infection caused by endemic treponematoses, which in Africa comprises yaws and endemic syphilis. ${ }^{3-5}$ Endemic treponematosis is usually contracted during childhood, and is typically confined to underprivileged population groups in remote areas with little or no access to health care and a low standard of hygiene. ${ }^{3}$ Endemic treponematoses have gained renewed attention during the past decade. After successful mass treatment campaigns by the WHO and UNICEF in the 1950 s and '60s, endemic foci remained and caused a resurgence of endemic treponematoses in South East Asia and parts of Africa during the past 20 years. Central and West Africa are most severely affected, but yaws has never been eradicated in any part of Africa, and a low level transmission has persisted. ${ }^{3}$

Reports of sexual abuse have been documented by the health service when children present with symptoms of sexually transmitted diseases (STDs) or injuries compatible with sexual abuse. A literature review of Medline on STDs and sexual abuse of children from 1986 to 1996 is presented in table $1 .^{6-21}$ Conclusions cannot be drawn regarding the prevalence of sexual abuse in the general population from this review of scattered hospital based research, but it demonstrates that sexual abuse of children does exist in Africa, and that girls seem to be at higher risk, from infancy to puberty and beyond.

Documentation of treponemal infection in children in the general population in areas of Africa with low prevalence for endemic treponematoses is limited, but some reports exist as seen in table $1 .^{6-9}$ In a Somali village, four cases out of 380 children had serological signs of active treponemal infection. ${ }^{6}$ In only one of these cases did the parents have positive serological markers. In rural Gambia, $1 \cdot 1 \%$ of 1872 children under 14 years of age had serological signs of active treponemal infection, but all were healthy and had no clinical signs of congenital or other treponemal infection. Among 397 randomly sampled healthy black children below 13 years of age in a township of Durban, South Africa, $1 \cdot 8 \%$ had serological, but no clinical signs of infection ${ }^{8}$; and among 1575 black schoolchildren, aged 6 to 18 in Bloemfontein, South Africa, $2 \cdot 0 \%$ had confirmed seropositive results. ${ }^{9}$ These studies were either population based ${ }^{6-8}$ or a survey of selected population groups of healthy children. ${ }^{9}$

So far, no serological, morphological, or biochemical examinations can distinguish the causative organisms of the different treponemal infections. ${ }^{22}$ However, testing of children and their parents will give useful information for interpreting serological test results for treponemal infection, in particular combined 
Table 1 Review of Medline references regarding STDs and sexual abuse of children in Africa, 1986-96

\begin{tabular}{|c|c|c|c|c|c|c|}
\hline Place & Study & Problem & No & $\begin{array}{l}\text { Age } \\
\text { (years) }\end{array}$ & $F / M$ & Ref no \\
\hline $\begin{array}{l}\text { Somalia, rural } \\
\text { Gambia, rural } \\
\text { Durban, SA } \\
\text { Bloemfontein, SA } \\
\text { Cape Town, SA } \\
\text { Nigeria } \\
\text { Abadan, Nigeria }\end{array}$ & $\begin{array}{l}\text { PB } \\
\text { PB } \\
\text { PB } \\
\text { SP } \\
\text { HB } \\
\text { HB } \\
\text { HB }\end{array}$ & $\begin{array}{l}\text { Syphilis survey } \\
\text { Syphilis survey } \\
\text { Syphilis survey } \\
\text { Syphilis survey } \\
\text { Sexual abuse } \\
\text { Gonorrhoea } \\
\text { Anogenital warts }\end{array}$ & $\begin{array}{r}380 \\
1872 \\
397 \\
1575 \\
18 \\
28 \\
148 \\
10\end{array}$ & $\begin{array}{l}0-15 \\
0-14 \\
0-13 \\
6-18 \\
2-12 \\
0-13 \\
0-49 \\
0-8\end{array}$ & $\begin{array}{l}0 \cdot 3 \\
1 \cdot 1 \\
1 \cdot 1 \\
4 \cdot 0 \\
8 \cdot 3 \\
-\end{array}$ & $\begin{array}{r}6 \\
7 \\
8 \\
9 \\
10 \\
11 \\
\end{array}$ \\
\hline Bujumbura, Burundi & HB & $\begin{array}{c}\text { Gonorrhoea, } \\
\text { sexual abuse }\end{array}$ & $\begin{array}{r}239 \\
25\end{array}$ & $0-10$ & $4 \cdot 0$ & 13 \\
\hline $\begin{array}{l}\text { Addis Ababa, Ethiopia } \\
\text { Kigali, Rwanda } \\
\text { Nairobi, Kenya } \\
\text { Zimbabwe, rural } \\
\text { Johannesburg, SA }\end{array}$ & $\begin{array}{l}\text { HB } \\
\text { HB } \\
\text { HB } \\
\text { HB } \\
\text { HB }\end{array}$ & $\begin{array}{l}\text { STDs in teenagers } \\
\text { Vulvovaginitis, sexual abuse } \\
\text { Sexual abuse } \\
\text { Sexual abuse, rape } \\
\text { Child abuse, }\end{array}$ & $\begin{array}{r}181 \\
567 \\
21 \\
18 \\
140\end{array}$ & $\begin{array}{r}13-19 \\
0-15 \\
0-18 \\
4-15\end{array}$ & $\begin{array}{l}\text { All F } \\
\text { All F } \\
\text { All F } \\
17 \cdot 0\end{array}$ & $\begin{array}{l}13 \\
14 \\
15 \\
16 \\
17\end{array}$ \\
\hline $\begin{array}{l}\text { Cape Town, SA } \\
\text { Durban, SA }\end{array}$ & $\begin{array}{l}\mathrm{HB} \\
\mathrm{HB}\end{array}$ & $\begin{array}{l}\text { sexual abuse } \\
\text { Sexual abuse } \\
\text { Child abuse, }\end{array}$ & $\begin{array}{r}114 \\
114 \\
88 \\
162 \\
27\end{array}$ & $\begin{array}{l}0-16 \\
0-13\end{array}$ & $\begin{array}{r}24 \cdot 0 \\
9 \cdot 0\end{array}$ & $\begin{array}{l}18 \\
19\end{array}$ \\
\hline Somalia, urban & SP & $\begin{array}{l}\text { sexual abuse } \\
\text { Sexual abuse }\end{array}$ & $\begin{array}{l}37 \\
95\end{array}$ & $\begin{array}{l}3-16 \\
6-14\end{array}$ & $\begin{array}{l}11 \cdot 3 \\
\text { All F }\end{array}$ & $\begin{array}{l}20 \\
21\end{array}$ \\
\hline
\end{tabular}

$\mathrm{PB}=$ population based; $\mathrm{SP}=$ selected population groups; $\mathrm{HB}=$ hospital based; $\mathrm{F}=$ females; $M=$ males; $\mathrm{SA}=\mathrm{South}$ Africa.

with data from medical history, clinical picture, and available epidemiological information. The present study was undertaken to determine the seroprevalence of treponemal infection and possible risk factors among children aged $0-14$ in the general population of a rural Tanzanian village. This study was conducted as part of a comprehensive HIV and STD survey of the total village population. ${ }^{23}$

\section{Subjects and methods}

The study was carried out from July 1991 to January 1992 at a temporary survey centre established in a village of the Kahe Ward in Kilimanjaro region, northern Tanzania. The village is located at the foot of Mount Kilimanjaro, only a few kilometres from the Tanzanian-Kenyan border, in the Tanzanian highlands, approximately 700 metres above sea level. The climate is warm and dry. Most of the villagers are farmers and some also keep goats or cattle. Some, mostly men, have paid work outside the village, and return home only to visit their wives and families. Kahe is considered to be a low socioeconomic area within Kilimanjaro region. The village does not have electricity. Lack of clean water is a constant problem, and people suffer from diseases caused by unclean water and poor hygiene. Both intestinal and urinary schistosomiasis were found. Malaria was hyperendemic, and a common reason for blood transfusions in children.

Research and ethical clearance for the survey of the total village population on HIV and STD was obtained both from Ministry of Health in Tanzania and the Norwegian Committee for Medical Research Ethics. Participation was based on informed, oral consent. Parents gave consent on behalf of children up to the age of 14. All participants had venous blood samples drawn for HIV testing and a structured medical history taken. Participants in the 15-44 age group were given a structured interview and were also screened for STDs. Thus, only parents younger than 45, with few exceptions, were tested for treponemal infection. In addition, the consecutive 500 children first attending were tested for treponemal infection. The analysis of data presented in this paper is based on these children, their parents, siblings, and other household members. A code number system for family member relations and households was worked out and applied to every participant. Treatment was given for curable diseases, including STDs, while HIV positive individuals were offered medical follow up and counselling.

Testing for treponemal infection included a rapid plasma reagin test (RPR; Syphacard-R, Murex diagnostics Ltd, Dartford), and a Treponema pallidum haemagglutination test (TPHA, Wellcosyph HA, Murex Diagnostics Ltd, Dartford), and was done according to manufacturer's instructions. During a short period when there were delivery problems and we could not obtain the RPR test, the Venereal Disease Research Laboratory (VDRL) test, was used instead. The non-treponemal tests, RPR/VDRL, and the specific treponemal test, TPHA, are well established. Used as a screening method in a low prevalence population, as in this study, the false positive rate for TPHA is about $1 \%$ and for RPR it may vary from $1-2 \%$ up to over $50 \% .^{24}$ It is recognised that the nontreponemal tests in a number of different medical conditions can transiently give false positive results after a variety of acute febrile illnesses, including malaria, after immunisations and during pregnancy, and chronic false positive tests occur in chronic infections such as leprosy, and in autoimmune diseases. We have used the TPHA test as an epidemiological screening tool. If both the RPR and the TPHA tests were reactive, it was considered to be an indication of active treponemal infection. If only the TPHA test was positive this was taken as a sign of previous treponemal infection. The RPR test was only done qualitatively, while the VDRL test was done quantitatively. The TPHA test was performed quantitatively, and titres are given in table 3. Unfortunately, two of the positive samples were not quantified for unknown reasons. A doubtful reaction was regarded as a negative test. Weakly reactive tests were considered positive both for the specific and non-specific treponemal tests. Blood samples were brought from the survey village every day, and tested on a daily basis at Kilimanjaro Christian 
Medical centre, the zonal hospital for northern Tanzania.

Among a total of 1708 registered children, the first 553 participated in the survey. The participating children belonged to a household cohort with a total of 1339 members, or $34.6 \%$ of the total eligible population in the village. In this household cohort 1224 , or $91.4 \%$, participated in the survey and $82.1 \%$ of these were tested for treponemal infection. The village was divided into so called 10 cell units comprising approximately 10 households, and these 10 cells were called in a random order. The HIV prevalence in the household cohort was practically identical to the prevalence in the rest of the village population; $0.7 \%$ versus $0.6 \%$ among males and $2.0 \%$ versus $1.9 \%$ among females. In this village we found only one girl, aged 4, to be HIV infected, and she did not belong to the household cohort. Among the age group 15-44, the overall TPHA prevalence was significantly lower $(p=0.03)$ in the household cohort $(5 \cdot 3 \%)$ than in the rest of the village population $(8 \cdot 8 \%)$. However, single females had approximately the same prevalence in the two groups $(7 \cdot 4 \%$ in the household cohort versus $6.9 \%$ in the rest of the population). This indicates that the household cohort did not represent a high risk group for treponemal infection compared with the rest of the village population. The age was significantly lower in the household cohort, which was expected since the selection was based on families with children.

A non-significant trend regarding polygamy existed. In the household cohort $24.5 \%$ of married women and $5 \cdot 1 \%$ of men were in a polygamous marriage, while in the rest of the population the respective percentages were $17 \cdot 7$ and $12 \cdot 7$; in the household cohort there were significantly more females in the age group 15-44 $(\mathrm{p}=0.01)$. However, the ratio between married and unmarried men and women did not differ in the two village groups (see Results).

Prevalences were analysed using descriptive statistics procedures. Bivariate analyses were performed using $\chi^{2}$ test and logistic regression analyses. Odds ratios (OR) and 95\% confidence intervals (CI) are presented. The data analyses were conducted using Statistical Package for Social Sciences version 6.1 (SPSS, Inc, Chicago, IL, USA).

\section{Results}

The overall prevalence for the TPHA test, indicating past or present treponemal infection, was $6 \cdot 4 \%$ among girls and $1 \cdot 1 \%$ among

Table 2 Prevalence of past or present treponemal infection by sex and age among rural children, Kilimanjaro, Tanzania

\begin{tabular}{|c|c|c|c|c|}
\hline \multirow{2}{*}{$\begin{array}{l}\text { Age } \\
\text { (years) }\end{array}$} & \multicolumn{2}{|l|}{ Girls } & \multicolumn{2}{|l|}{ Boys } \\
\hline & No $+/$ tested & $\%$ & $\mathrm{No}+$ /tested & $\%$ \\
\hline $\begin{array}{c}0-4 \\
5-9 \\
10-14 \\
\text { Total }\end{array}$ & $\begin{array}{r}2 / 81 \\
5 / 96 \\
10 / 89\end{array}$ & $\begin{array}{r}2 \cdot 5 \\
5 \cdot 2 \\
11 \cdot 1\end{array}$ & $\begin{array}{l}0 / 96 \\
2 / 89 \\
1 / 102\end{array}$ & $\begin{array}{l}0 \\
2 \cdot 2 \\
1 \cdot 0^{\star}\end{array}$ \\
\hline $0-14$ & $17 / 266$ & $6 \cdot 4$ & $3 / 287$ & $1 \cdot 1 \dagger$ \\
\hline
\end{tabular}

${ }^{\star} P=0.002,+P=0.0008 . \ddagger$ The TPHA test was used boys $(\mathrm{OR}=6 \cdot 5 ; \mathrm{CI}: 1 \cdot 9-22 \cdot 3)$. In all age groups the prevalence rates among girls were higher compared with boys both for the RPR and the TPHA tests; however, significantly only for the TPHA test. The sex difference was most pronounced in the 10-14 age group for the TPHA test (OR $=12.8 \mathrm{CI}: 1 \cdot 6-$ $101.9)$ as shown in table 2.

Among parents, older siblings, and other household members in the age group 15-44, women had a non-significantly higher overall prevalence of TPHA, compared with men $(5 \cdot 8 \%$ versus $4 \cdot 4 \%, \mathrm{OR}=1 \cdot 3$; CI: $0.5-3 \cdot 4)$, and of active treponemal infection $(2 \cdot 1 \%$ versus $0 \cdot 6 \%, \mathrm{OR}=3 \cdot 3$; CI: $0 \cdot 4-28 \cdot 9$ ). Married women and men had nearly identical overall prevalence rates of TPHA $(4 \cdot 8 \%$ versus $4 \cdot 7 \%$ ). Single women had a higher prevalence of TPHA than single men $(7 \cdot 4 \%$ versus $4.4 \%$, $\mathrm{OR}=1 \cdot 8 ; \mathrm{CI}: 0 \cdot 5-6 \cdot 2)$.

In table 3 , an overview of children who tested positive for one or both of the treponemal tests, and the corresponding available test results for their parents, are presented. Among the 20 children who were TPHA positive, we know the serostatus of both parents in seven cases. All the parents were TPHA negative; we further know the TPHA test results for the mothers of 14 children. One 25 year old single mother was HIV, VDRL, and TPHA positive. Both her daughters, aged 4 and 6 years, were HIV negative, but VDRL and TPHA positive, and they probably represent cases of congenital syphilis (family 2). These are the only two cases found indicating active treponemal infection. In all other cases where we know the TPHA status of the mother, she was negative. In one case we know the status of the father only, who, like his 12 year old son, was positive. Since we do not know the status of his mother, we cannot be conclusive, but this might also be a case of congenital syphilis (family 17). This case could also be a third case of active treponemal infection, considering the high TPHA titre. However, his RPR test results are missing, so we do not know if this is a past or present infection. Thus, among the 15 TPHA positive cases where we know the parents' test results, only two cases seem to be congenital syphilis, and one other case might be. In four cases we do not know the serostatus of any of the parents because four girls lived with their grandmothers/parents. Three of them, aged 3,10, and 11 years, were TPHA positive (families $6,15,16$ ).

Among the 28 children who were positive for either one or both tests, 14 cases came from six families. In four families, two or more daughters tested positive (families $1,2,4,5$ ). Furthermore, both a daughter and a granddaughter in family 3 and a son and a granddaughter in family 6 tested positive. In one family, three teenage girls aged 13,13 , and 14 years, were TPHA positive, while both mothers in this polygamous marriage and their father were TPHA negative (family 1 ).

Among the 553 children who were tested for treponemal infection $8.3 \%(n=46)$ had had blood transfusions during the last 10 years. The mean number of injections during 
Table 3 Overview of test results for treponemal infection and age among children who tested positive and their parents/superiors

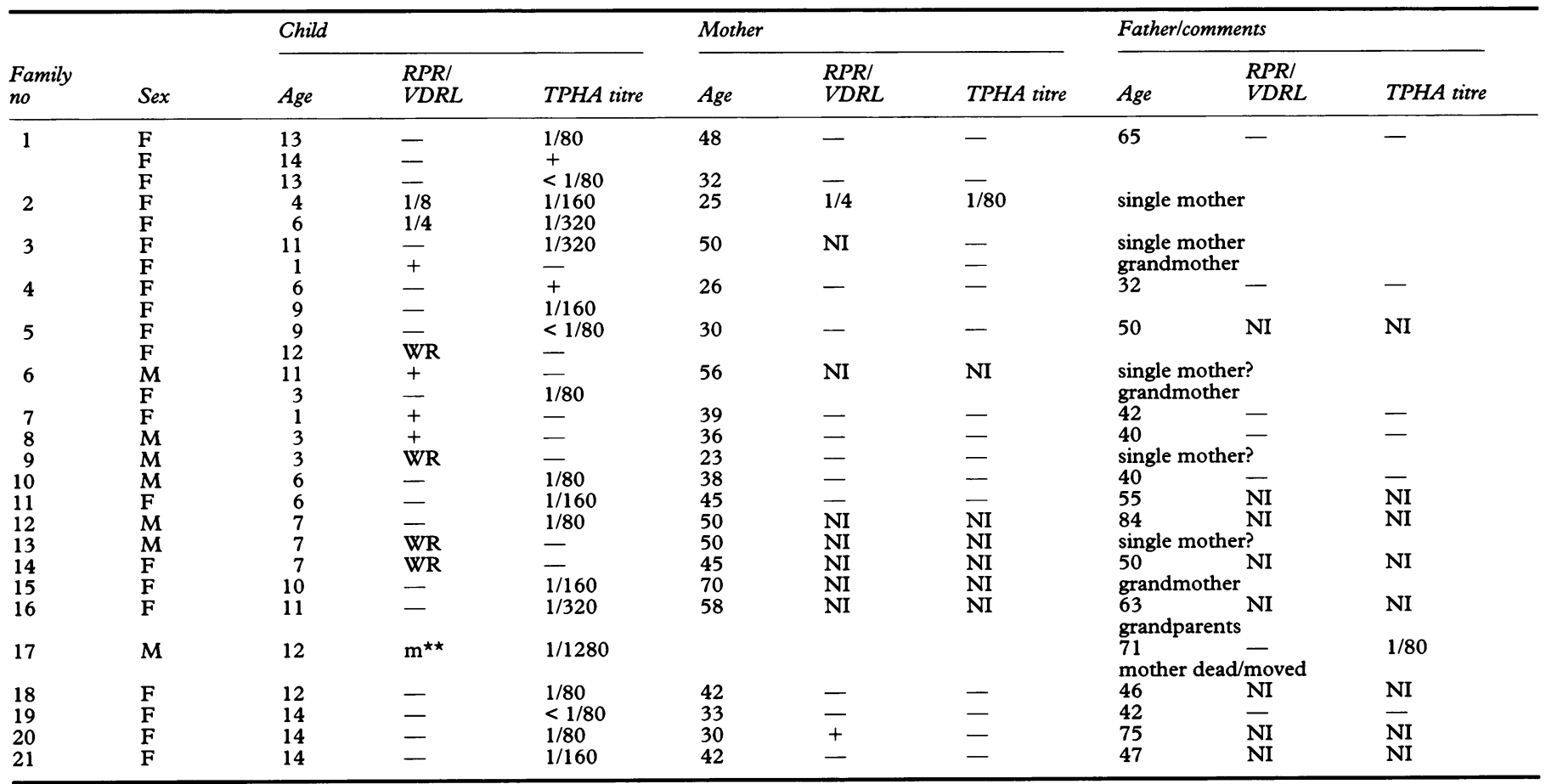

$\star \mathrm{NI}=$ not included.

the last 10 years were 10.5 (SD 8.8) for girls and $6.5(6 \cdot 7)$ for boys. No significant associations between treponemal infection and blood transfusions or injections were found.

\section{SEXUAL DEBUT AND MARITAL PATTERN}

In the age group 15-44 there was a distinctly different marital pattern between males and females. While $61.0 \%$ of the females were married, this was the case for only $42.0 \%$ of the males. Comparing women and men, we found there was a shorter time from mean age of sexual debut $(17.3(2 \cdot 8)$ versus $16.2(3.8))$ to marriage age $(18.3(3.3)$ versus $24.9(5 \cdot 3))$. Among men, $25 \%$ had had their first intercourse by age 14, while among women this was 15 years of age. Among men, $14.8 \%$ claimed that they had had their sexual debut at age 12 or younger, while only $2 \cdot 1 \%$ of women reported the same.

\section{Discussion}

In this rural Tanzanian village population, we have found serological signs of treponemal infection in children under 15 years of age. There are two striking findings in our study. Firstly, the strong association between sex and positive serology, putting girls at a greater risk for infection than boys. Secondly, the apparent lack of an association between positive serology in children and positive serology in their parents, either mothers or fathers.

In the few available studies of treponemal infection in children in the general population no similar sex difference as documented in this study, has been found ${ }^{6-9}$ (table 1). Yaws is transmitted by direct, personal skin to skin contact, and endemic syphilis is transmitted both directly by skin to skin and mouth to mouth contact and indirectly by contaminated fingers and drinking utensils. ${ }^{45}$ In the survey village, girls and boys did not live separated from each other. We, therefore, do not assume that there should be any sex difference regarding possible transmission of endemic treponematosis. Most authors assume no sex difference in transmission rates among girls and boys. The highly significant sex difference (OR $=6.5$ in favour of girls testing positive for TPHA) and the concomitant lack of association between mother's and children's serostatus point to sexual transmission as the most likely route of transmission of treponemal infection in girls during childhood. Consequently, the most common treponemal infection in girls was venereal syphilis. We regard this as the most plausible interpretation of the serological test results. However, the seropositive children in this study were not examined clinically, as this study was not designed to investigate sexual abuse of children. Hence, we cannot verify this interpretation through documentation of clinical signs of sexual abuse.

Married women and men in this family cohort had nearly identical prevalences of TPHA. The pattern seen is that seropositive daughters have seronegative mothers, and that seropositive parents do not have seropositive children, except for two cases of congenital syphilis. The sources of infection for the seropositive girls are, therefore, possibly found outside the family. Even though we lack the serostatus for more than half of the fathers, it is reasonable to assume that most are negative, since their wives are negative. However, we cannot be conclusive, since transmission of active syphilis between sexual partners was shown to be as low as $18.1 \%$ in a study from a semirural community in Gabon. ${ }^{25}$

In a traditional African society, adult men's sex with underage girls cannot by definition be described as sexual abuse of children in the 
Western sense of the concept. In various ethnic groups in Tanzania, sex between adult men and prepubescent girls is accepted, ${ }^{26}$ and similar practice is documented from other African countries. ${ }^{27}{ }^{28}$ During the 1988 population census in Tanzania, $0.5 \%$ of men and $1 \cdot 1 \%$ of women were reported to be married at the age of 10 to 14 . In the census in 1967, $3.2 \%$ of women reported a correspondingly low marriage age. ${ }^{29}$ In an STD study of 2111 unselected women in Addis Ababa, half of the women had their first intercourse before menarche which in this population occurred at a mean age of $15,20.0 \%$ had their sexual debut when they were younger than 13 years, and $99.4 \%$ were virgins at the time of their first marriage. ${ }^{27}$ In the survey village, a few women and men reported having had their sexual debut as early as 6-7 years of age, even though the mean age was much higher. This information, obtained through standardised questionnaires, is difficult to interpret. Reported sexual debuts might represent all from children's sex play, to sexual abuse and completion of penetrative sex with a gradual transition to a "traditional" relationship between an adult man and a girl. It might also reflect a potential misunderstanding of the age terms among the respondents. Most adult villagers could read and write, but the level of education was generally low. The dominant ethnic groups in the survey village did not practise sex before puberty but, traditionally, girls used to get married at a younger age than boys, and frequently to older men. ${ }^{30}$

While marriage of prepubertal or very young girls is a traditional pattern in various African ethnic groups, in the era of AIDS, anecdotal reports have said that adult men who want casual sex should seek female sexual partners at a younger and younger age to avoid HIV infection. The TPHA prevalence of $11 \cdot 1 \%$, found among girls aged 10-14 might be an indication that this is the case in the Kahe survey village. It is, moreover, an indication that this age group of young girls is highly at risk to acquire HIV infection at a later stage in the HIV epidemic, when the prevalence among adult men might be higher than the $2.5 \%$ found at the time of the survey. There was also a "marriage gap" between males and females in this population, which possibly adds sexual pressure on the younger girls. While women tended to marry at an early age, men had a median age for marriage of 25 , and nearly $60 \%$ of the men in the $15-44$ age group were not married. The reporting of AIDS cases in Tanzania also confirms the vulnerability of young girls for HIV infection. While the overall female/male ratio is 1.2 , this ratio is nearly four to one in the 15-19 age group, and 2.5 in the $20-25$ age group, indicating that girls are HIV infected at an early age. ${ }^{31}$ This is illustrated by the fact that during a syphilis epidemic among the ethnic group Maasai, girls estimated to be as young as 9 years contracted the disease. ${ }^{26}$

The review of Medline presented in table 1 indicates that girls are brought more often to hospital with symptoms of STDs or injuries compatible with sexual abuse, than are boys. Among adults the opposite is the case: men seek treatment for symptoms of STDs more often than women. ${ }^{32}$ In this population based study, we found the same tendency as seen in the hospital based research

When conducting our survey, we wanted to see if there were any subclinical cases of nonvenereal treponemal infection. Among participating boys, three cases were identified as TPHA positive. Two of their mothers were negative, the third mother's serostatus was unknown. These cases and a similar fraction of cases among the girls may represent endemic treponemal infections. All the TPHA positive boys were 6 years or older. The peak incidence of yaws occurs between 6 and 10 years of age in endemic areas. ${ }^{33}$ However, even among boys, the possibility of sexual abuse should not be ruled out. Skin diseases like scabies and fungal infections were common, and no typical case of yaws or endemic syphilis was reported. Some authors have described an "attenuated" picture of endemic treponematosis after the mass campaigns with less distinct symptoms. ${ }^{34}$ In the Kahe survey village both oral use of antibiotics, and penicillin injections were common. This may heal or mask both the venereal and non-venereal treponemal infection. The infection will, however, still induce an antibody response which results in a positive TPHA test for life, and this may explain the relatively low prevalence of $R P R$ seen in this population.

\section{Conclusion}

We suggest that most of the treponemal infections in girls seen in this village population may be venereal syphilis as this is the most reasonable interpretation of the highly significant sex difference in favour of girls testing positive for TPHA. However, our serological data do not indicate that this is transmitted by incest from fathers to daughters. The sources of infection for the seropositive girls are possibly found outside the family. The high percentage of unmarried men in this population combined with the growing awareness of the HIV epidemic and the search among men for a "clean" sexual partner may offer a hypothesis that some single men have sex with underage girls. Further research is needed to confirm or reject this hypothesis.

This work was supported by grants from the Norwegian Agency for Development Cooperation (NORAD) through the Tanzanian Norwegian AIDS Project (MUTAN) and the Norwegian Research Counci.

We thank the people of the survey village and their village government for support and participation in the project. We further thank the field team and the laboratory reseach staff at Kilimanjaro Christian Medical Centre, the MUTAN office staff, the district and regional health authorities in Kilimanjaro, and the Ministry of Health in Tanzania for supporting this project. We also thank Dr W P Howlett, King's College Hospital, London, and Dr B Hederstedt, Stockholm, for commenting on an early draft of this paper. We are greatly indebted to University of Bergen/Institute for Nutrition Research, University of Oslo, our scientific adviser.

1 Richens J. Sexually transmitted diseases in children in developing countries Genitourin Med 1994;70:278-83.

2 Rawstron SA, Bromberg K, Hammerschlag MR. STD in children: syphilis and gonorrhoea. Genitourin Med 1993; 
69:66-75.

3 Meheus A, Antal GM. The endemic treponematoses: not yet eradicated. World Health Stat $Q$ 1992;45:228-37.

4 Engelkens HJ, Judanarso J, Oranje AP, Vuzevski VD, Niemel PL, van der Sluis J, et al. Endemic trepon
matoses. Part I. Yaws. Int $\mathcal{F}$ Dermatol 1991;30:77-83. 5 Engelkens HJH, Niemel PLA, van der Sluis JJ, Meheus A,
Stolz E. Endemic treponematoses. Part II. Pinta and endemic syphilis. Int $\mathcal{F}$ Dermatol 1991:30:231-7.

6 Ismail SO, Ahmed HJ, Jama MA, Omer K, Omer FM Brundin $M$, et al. Syphilis, gonorrhoea and genita chlamydial infection in a Somali village. Genitourin Med 1990;66:70-5.

7 Greenwood AM, D'Alessandro U, Sisay F, Greenwood $B M$. Treponemal infection and the outcome of pregnancy in a rural area of the Gambia, West Africa. $\mathcal{F}$ Infect nancy in a rural area

8 Coovadia YM. A community-based seroprevalence survey of syphilis in black children. Genitourin Med 1990;66: $124-6$.

9 van Niekerk $C H$, van Niekerk LC, van den Ende J. Positiewe serologiese toetse vir sifilis by swart laerskoolkinders van Bloemfontein. S Afr Med $\mathcal{F}$ 1985;67: 90-1.

10 Westcott DL. Sexual abuse of children. A hospital-based study. S Afr Med F 1984;65:895-7.

11 Odugbemi T, Onile BA. Pediatric gonorrhoea: is it receiving adequate attention? Am $\mathcal{F}$ Reprod Immunol Microbiol 1988 18:32-4.

12 Ekweozor CC, Adeyemi-Doro FAB, Ashiru JO, Osoba AO Anogenital warts in patients attending the sexually transmitted diseases clinic in Ibadan, Nigeria. Afr $f$ Med $S$ 1994;23:311-4.

13 Baribwira C, Muteganya D, Ndihokubwayo JB, Moreno $J$, Nduwimana M, Rufyikiri T. An aspect of sexually transmitted diseases in infants in Burundi: gonorrhoea due to sexual abuse. Med Trop 1994;54:231-3.

14 Duncan ME, Tibaux G, Pelzer A, Mehari L, Peutherer J, Young $\mathrm{H}$, et al. Teenage obstetric and gynaecologica problems in an African city. Cent Afr $\mathcal{F}$ Med 1994;40: $234-44$.

15 Bogaerts J, Lepage $P$, De Clercq $A$, Mukeshimana $M$ Serufiliva $S$, Piot $P$, et al. Shigella and gonococcal vulvovaginitis in prepubertal central African girls. Pediatr Infect vaginitis in prepubertal

16 Nduati RWK, Muita JWG. Sexual abuse of children as seen at Kenyatta National Hospital. East Afr Med $\mathcal{F} 1992$ 69:350-4

17 Drew RS. Sexual abuse of children in rural Zimbabwe: a report from Elim Hospital. Trop Doc 1994;24:81.

18 Howard PA, Marumo LP, Coetzee DJ. Child abuse in Alexandra. A clinic-based study and a community programme. S Afr Med $\mathcal{f} 1991 ; 80: 393-6$

19 Jaffe AM, Roux P. Sexual abuse of children-a hospitalbased study. $S$ Afr Med 7 1988;74:65-7.

20 Haffejee IE. Sexual abuse of Indian (Asian) children in
South Africa: first report in a community undergoing cultural change. Child Abuse Negl 1991;15:147-51.

21 Ahmed HJ, Ilardi I, Antognoli A, Leone F, Sebastiani A Amiconi G. An epidemic of Neisseria gonorrhoeae in a Amiconi G. An epidemic of Neisseria gonorrho

22 Noordhoek GT, Cockayne A, Schouls LM, Meloen RH, Stoltz E, van Embden JDA. A new attempt to distinguish serologically the subspecies of treponema pallidum causing syphilis and yaws. F Clin Microbiol 1990;28:1600-7.

23 Klouman E, Masenga EJ, Klepp K-I, Sam NE, Nkya W, Nkya C. HIV and reproductive tract infections in a tota village population in rural Kilimanjaro, Tanzania: Women at increased risk. F Acquir Immune Defic Syndr Hum Retrovirol 1997;14:163-8.

24 Larsen SA, Hunter EF, Creighton ET. Part Vlll Chapter 75. Diagnostic testing for syphilis. In: Holmes $\mathrm{KK}$, Mårdh PA, Sparling PF, Wiesner PJ, eds. Sexually trans Mărdh PA, Sparling PF, Wiesner PJ, eds. Sexually transmitted diseases. New York: Macice
Service Company, 1990:927-34.

25 Schrijvers D, Josse R, Trebucq A, Dupont A, Cheringou $\mathrm{H}$, Larouzé $B$. Transmission of syphilis between sexual partners in Gabon. Genitourin Med 1989;65:84-5.

26 Talle A. Desiring difference: risk behaviour among young Maasai men. In: Klepp K-I, Biswalo PM, Talle A, eds Young people at risk. Fighting AIDS in Northern Tanzania. Oslo: Scandinavian University Press, 1995:69-85.

27 Duncan ME, Tibaux G, Pelzer A, Reimann K, Peutherer JF, Simmonds $P$, et al. First coitus before menarche and risk of sexually transmitted disease. Lancet 1990;335: risk of $338-40$.

28 Caldwell JC, Caldwell P, Orubuloye IO. The family and sexual networking in Sub-Saharan Africa: historical regional differences and present-day implications. Popul Stud 1992;46:385-410.

29 Leshabari MT. Young women at risk. Paper presented at the Mutan Harvest Seminar, University of Bergen, 24-25 August 1995.

30 Heguye ES. Young people's perception of sexuality and and condom use in Kahe. In: Klepp K-I, Biswalo PM Talle A, eds. Young people at risk. Fighting AIDS in Northern Tanzania. Oslo: Scandinavian University Press, 1995:113-20.

31 Swai RO. HIV/AIDS epidemiology in Tanzania. Mutan Harvest seminar, University of Bergen, 24-25 August 1995.

32 Piot $P$, Laga $M$. Current approaches to sexually transmitted disease control in developing countries. In Wasserheit JN, Aral SO, Holmes KK, eds. Research issues in human behavior and sexually transmitted diseases in the Aids era. Washington: American Society for Microbiology, 1991:281-95.

33 Sehgal VN, Jain S, Bhattacharya SN, Thappa DM. Yaws control/eradication. Int $\mathcal{F}$ Dermatol 1994;33:16-20.

34 Vorst FA. Clinical diagnosis and changing manifestations of treponemal infection. Rev Infect Dis 1985;7(suppl 2): 327-31. 